Prepared for the National Biodefense Analysis and Countermeasures Center (NBACC)

\title{
Morphing Terminology Study
}

\author{
SJ Rose \\ DW Engel \\ FJ Brockman \\ ML Hart \\ NB Valentine \\ AJ Calapristi
}

June 2010

Pacific Northwest

NATIONAL LABORATORY

Proudly Operated by Baltelle Since 1965 


\title{
DISCLAIMER
}

This report was prepared as an account of work sponsored by an agency of the United States Government. Neither the United States Government nor any agency thereof, nor Battelle Memorial Institute, nor any of their employees, makes any warranty, express or implied, or assumes any legal liability or responsibility for the accuracy, completeness, or usefulness of any information, apparatus, product, or process disclosed, or represents that its use would not infringe privately owned rights. Reference herein to any specific commercial product, process, or service by trade name, trademark, manufacturer, or otherwise does not necessarily constitute or imply its endorsement, recommendation, or favoring by the United States Government or any agency thereof, or Battelle Memorial Institute. The views and opinions of authors expressed herein do not necessarily state or reflect those of the United States Government or any agency thereof.

\author{
PACIFIC NORTHWEST NATIONAL LABORATORY \\ operated by \\ BATTELLE \\ for the \\ UNITED STATES DEPARTMENT OF ENERGY \\ under Contract DE-AC05-76RL01830
}

Printed in the United States of America
Available to DOE and DOE contractors from the Office of Scientific and Technical Information,
P.O. Box 62, Oak Ridge, TN 37831-0062;
ph: (865) 576-8401
fax: $(865)$ 576-5728
email: reports@adonis.osti.gov

\begin{abstract}
Available to the public from the National Technical Information Service, U.S. Department of Commerce, 5285 Port Royal Rd., Springfield, VA 22161 ph: (800) 553-6847 fax: $(703) 605-6900$ email: orders@ntis.fedworld.gov online ordering: http://www.ntis.gov/ordering.htm
\end{abstract}

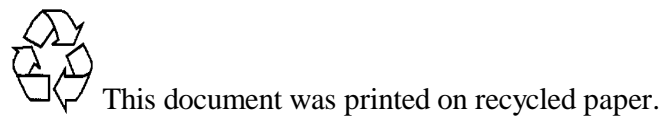


PNNL- 19493

\title{
Morphing Terminology Study
}

\author{
SJ Rose DW Engel \\ FJ Brockman NB Valentine \\ ML Hart AJ Calapristi
}

June 2010

Prepared for the National Biodefense Analysis and Countermeasures Center (NBACC)

Pacific Northwest National Laboratory

Richland, Washington 99352 



\begin{abstract}
This study investigates methods of automatically identifying and characterizing significant transitions in term usage over time. Within scientific literature, the occurrence of terms reflects the use of technologies and techniques as well as the study of specific species and materials. Transitions in terminology usage may be a result of vocabulary standardization or specialization in which terms are replaced with their shorter form. They may also be a result of new applications, combinations, alternatives, or interests that result in the appearance of new or existing terminology in unexpected contexts.
\end{abstract}





\section{Summary}

Observations of term usage over time in scientific literature have shown clear emergence of certain terms and phrases. However, in many cases these "emergent terms" eventually lose their emergent signatures (i.e., occurrences of the term diminish) even though domain experts identified that the technology actually continued to advance. The hypothesis is that when a new technology emerges, the vocabulary associated with that technology becomes more specialized and changes (morphs) into new, but related, terminology. This study reports research on methods to automatically capture these phenomena and incorporate them into emergence detection algorithms and visual representations.

We demonstrate application of several methods that support the identification of morphing terminology and terminology transitions over time that aid users in identifying new technologies and their precursors, as well as new applications and combinations of science and technology. We expect that users will have an interest in exploring terminology transitions in relation to a focused context, defined through a set of documents, search terms, or computed themes. Temporal analysis of terms' document occurrences, co-occurrences, and associations within the user-defined context will reveal terms that are transitioning into or out of that context. The comparison of terms' feature associations and document associations provides a means to evaluate whether terms are being used as expected, or whether they are dropping out of (or into) a given context unexpectedly. This method also enables identification of terms that should appear in documents together based on their feature associations, regardless of whether they do in fact co-occur within documents. 



\section{Acronyms and Abbreviations}

PCR

RAKE

SME

Energence

Feature

Term

Term Association

Term Document

Occurrences

Term Document

Co-occurrences

Term Document

Association

Term Feature

Association

Term-pair

Surprise

Root Term
Polymerase Chain Reaction

Rapid Automatic Keyword Extraction

Subject Matter Expert

\section{Glossary}

Algorithms to detect increasing or decreasing trend in topic

A term or attribute within a document

Single word or multi-word noun or phrase

Measurement of a term's association with a document, feature, or term

Number of documents in which a term occurs

Number of documents in which two terms co-occur

Number of occurrences of a term in a document

Number of occurrences of a term in documents with a given feature

Two terms that are being compared

Algorithms for detecting sudden event occurrence

A term of particular interest for a user and that provides a context for analysis 



\section{Contents}

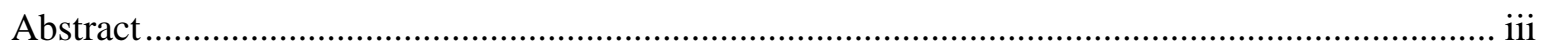

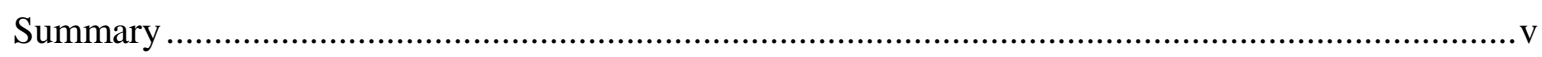

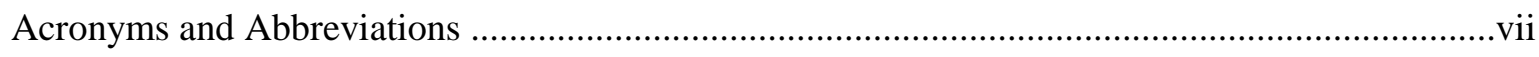

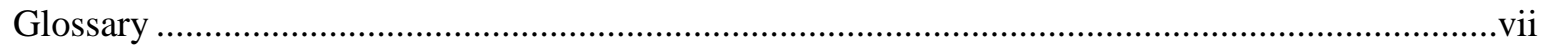

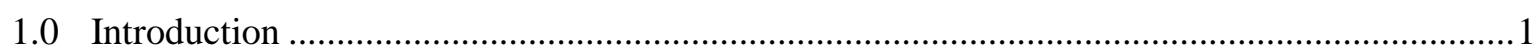

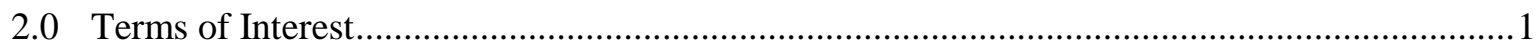

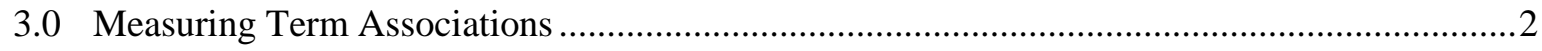

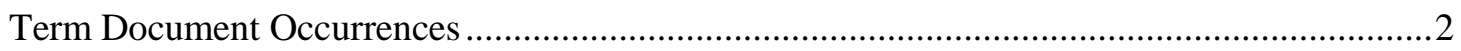

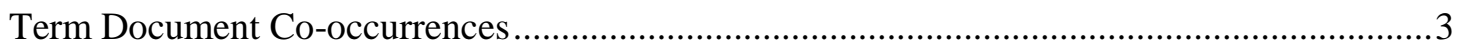

Term Document Associations ......................................................................................

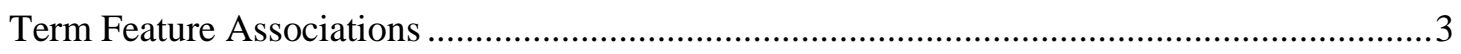

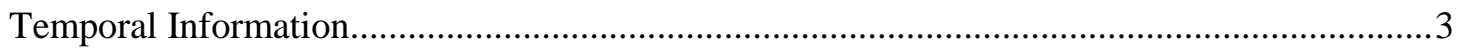

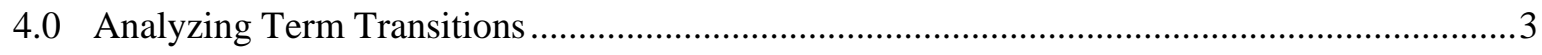

Temporal Analysis of Term Document Occurrences ..........................................................4

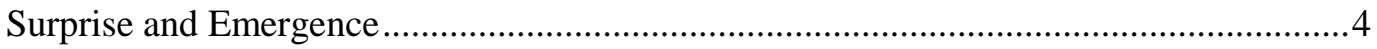

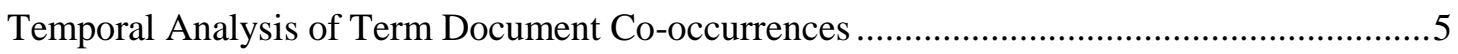

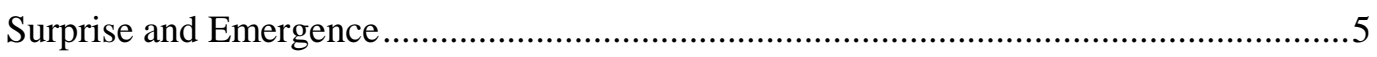

Ranking Terms by Variance Over Time …............................................................

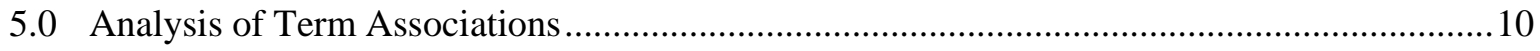

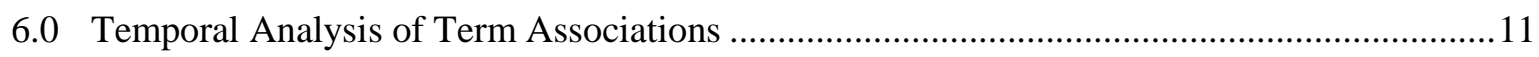

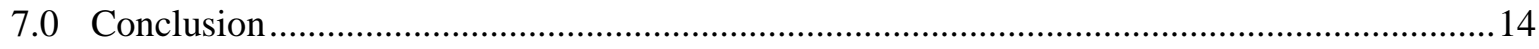

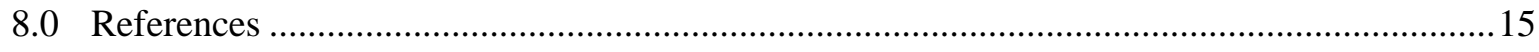

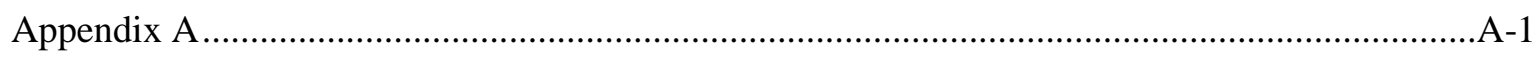




\section{Figures}

Figure 1 Histogram of document frequency for all documents (top profile) and the top 5 occurring terms normalized by maximum profile frequency (left plot) and normalized by maximum of all document profile (right plot), for the BioTechniques dataset.

Figure 2 Temporal distribution of documents within the BioTechniques dataset, using two

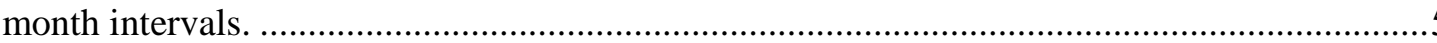

Figure 3 Temporal profiles of document frequencies for the term polymerase chain reaction, along with terms with increasing occurrences close to the same time (BioTechniques dataset).

Figure 4 Temporal profiles of term-pair co-occurrences (left plot) and document frequencies (right plot) for the term polymerase chain reaction and related terms (BioTechniques dataset).

Figure 5 The dimensions of feature association and document association, with representative cells color encoded by the difference of document association and feature association at their respective location in the context of a defined root term. 


\section{Tables}

Table 1 Term-pair co-occurrences of polymerase chain reaction and related terms in late 1991....7

Table 2 Terms sorted by sum of document co-occurrences with polymerase chain reaction.......... 7

Table 3 Terms sorted by standard deviation of yearly document co-occurrences with polymerase

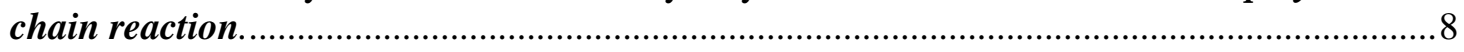

Table 4 Terms sorted by standard deviation of yearly relative proportion with polymerase chain

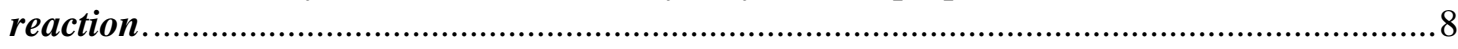

Table 5 Terms sorted by standard deviation of yearly relative proportion with $\mathbf{p c r}$....................... 9

Table 6 Similarity of terms' document associations by year to the document associations for the

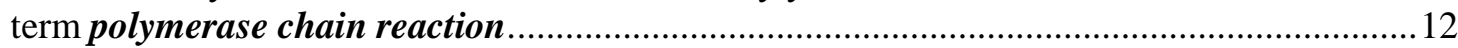

Table 7 Similarity of terms' feature associations by year to the feature associations for the term

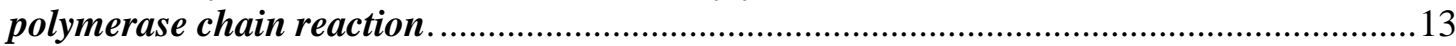

Table 8 Difference of similarities (Table 6-Table 7) for document associations and feature associations by year to the term polymerase chain reaction.

Table 9 Difference of similarities for document associations and feature associations by year to the term pcr. 



\subsection{Introduction}

This study investigates methods of automatically identifying and characterizing significant transitions in term usage over time. Within scientific literature, the occurrence of terms reflects the use of technologies and techniques as well as the study of specific species and materials. Transitions in terminology usage may be a result of vocabulary standardization or specialization in which terms are replaced with their shorter form, such as Escherichia coli $\rightarrow$ E. coli, or polymerase chain reaction $\rightarrow$ pcr. They may also be a result of new applications, combinations, alternatives, or interests that result in the appearance of new or existing terminology in unexpected contexts. As expertise within a particular area develops, established topical areas may generate specialized sub-topics that focus on further developing specific scientific or operational aspects of a technology or research field.

Our initial tests focus on scientific literature that has been subjected to peer review prior to acceptance for publication. Peer review affects scientific literature by standardizing terminology and by reducing the redundancy of published material (in contrast with news sources, which frequently republish material). Transitions in terminology therefore likely reflect real changes in the sciences.

While the methods presented here may identify significant morphing terminology, the real significance of these transitions as insight to actual developments can only be evaluated by an informed and interested user. Therefore, this study will focus on defining the underlying information, assumptions, and utility for each method and on effective ways of presenting each method's results to a user.

\subsection{Terms of Interest}

We generally define a term as a single word or multi-word noun or phrase that conventionally labels a specific or general subject. Typical terms of interest may be highly specific, such as Escherichia coli, or very general, as synthesis, and their appearance in text documents may be very common, such as dna, or infrequent, as mutagenic primers. Statistics associated with the usage of these terms not only provide insight into the topical content but also can provide insight into how topics change over time.

In literature, these terms of interest belong to a larger class of content-bearing words and are distinct from function words in a language, such as the English function words and, of, the, and for, which occur in many documents. Because function words appear in documents independent of their content, they will have distribution patterns that are distinct from content-bearing words, which typically occur in clumps, or clusters, of related documents [Bookstein 1998].

For the purposes of this study, terms of interest occurring in the source documents are selected through the application of the Rapid Automatic Keyword Extraction (RAKE) method. RAKE automatically extracts keywords from individual documents and aggregates statistics across a set of documents to identify content-bearing keywords and keyphrases [Rose 2010]. These are our "terms of interest." We also refer to these terms of interest as features of the documents in which they occur. Appendix A lists the top 200 terms of the 2614 identified by RAKE for the BioTechniques dataset. This dataset comprises 5693 abstracts from the journal BioTechniques ${ }^{l}$ from 1988 through 2008.

\footnotetext{
${ }^{1}$ BioTechniques, The International Journal of Life Science Methods, http://biotechniques.com
} 
In order to apply the methods outlined in this study, a set of documents, such as technical abstracts, that includes each document's publication date is needed. This unstructured source information is processed to generate a list of terms of interest, a concordance (or inverted index) that provides access to the frequency of each term within each document, and a mapping of each document to its publication date. Taken together, this information can be applied to measure each term's document frequency, document associations, and feature associations across the entire time range or within arbitrarily defined time intervals.

\subsection{Measuring Term Associations}

Term associations provide a means to characterize and compare terms across documents within a collection, or dataset, and are measured as term document occurrences, term document co-occurrences, term document associations, and term feature associations. All term measurements are fundamentally based on counts of term document occurrences and co-occurrences with other terms (features).

\section{Term Document Occurrences}

Term document occurrences represent the number of documents in which a given term occurs. Occurrences can be aggregated into histograms or raw counts for sets of documents to indicate counts for specific time intervals and groups within the dataset. The Facets and Time tools within IN-SPIRETM v5.0 ${ }^{2}$ provide examples of the analytic utility of this straightforward approach. While relative proportions to the dataset are not calculated, overlapping histograms can provide a means for the user to infer proportions relative to the larger context. As an example, Figure 1 shows the top 5 frequently used terms from the BioTechniques dataset. The left plot represents the number of documents for each term, where each term profile is scaled $(0,1)$. The right plots show the same terms, but they are scaled to all of the documents. The top profile of each plot shows the temporal profile of all the documents scaled $(0,1)$.

(1)

Figure 1 Histogram of document frequency for all documents (top profile) and the top 5 occurring terms normalized by maximum profile frequency (left plot) and normalized by maximum of all document profile (right plot), for the BioTechniques dataset.

${ }^{2}$ IN-SPIRE ${ }^{\mathrm{TM}}$ Visual Document Analysis, http://in-spire.pnl.gov 


\section{Term Document Co-occurrences}

Term document co-occurrences reflect the number of documents in which two terms co-occur. Terms that co-occur within documents are considered to be associated. For a set of documents, this association is characterized as strong if the terms frequently co-occur. If the set of documents is filtered to only include documents containing a defined root term, then term document occurrences are identical to term document co-occurrences with the root term.

\section{Term Document Associations}

Term document associations represent the association of a term with individual documents. These may be calculated as the count of term occurrences within a document or as a normalized score. For this evaluation, we calculated each term's document association as the count of its occurrences within the document.

\section{Term Feature Associations}

Within this study, a feature is a term of interest. Term feature associations represent the association of a term with other terms. This association is calculated as the count of the term's document co-occurrences with another term. A term's feature association vector represents its related terms and is similar to terms that are related to the same terms even if they occur in different documents.

\section{Temporal Information}

Each of the methods for evaluating term characteristics can be further applied to specific time intervals as well as across the entire time range. This enables finer-grained insight to terminology dynamics as term associations will change over time.

\subsection{Analyzing Term Transitions}

Because transitions of term usage occur over time, we have investigated several methods for the temporal analysis of term usage statistics. Regardless of the method selected, many analyses will focus on a specific set of documents within which to investigate transitions within a larger dataset. This document context may be obtained by a specified root term, search criteria, selected theme, or documents from a particular source. Each of the methods described for measuring term associations will effectively count term-occurrence statistics solely from documents within the current document context. A user is therefore able to define a document context and identify terms whose usage changes within those documents over time. When the document context is defined by a specific root term, such as pcr, the change over time of an individual term's occurrences within the document context reflects increasing or decreasing usage of the term with the root term.

Each of the methods is applied to the known transition from polymerase chain reaction to pcr as this is a known example upon which we can more effectively evaluate and compare these methods. 


\section{Temporal Analysis of Term Document Occurrences}

\section{Surprise and Emergence}

To find candidate morphing terms, our Surprise algorithms for detecting trends can be used [Engel 2010 and Engel 2009]. In these algorithms, the first step is to bin each term's document occurrences into time intervals. Then a comparison of the document occurrence counts in two adjacent time windows for a specific term is performed in order to identify a significant change in document counts between the two windows. The Emergence statistic for decreasing trends can be used to order the most significant candidate terms by using the following hypothesis test:

$$
\begin{aligned}
& H_{o}: \frac{1}{n c} \sum_{j=i}^{i+n c} x_{j}=\frac{1}{n c} \sum_{j=i-n p}^{i-1} x_{j} \\
& H_{a}: \frac{1}{n c} \sum_{j=i}^{i+n c} x_{j}<\frac{1}{n c} \sum_{j=i-n p}^{i-1} x_{j}
\end{aligned}
$$

The symbol $n p$ represents the number of time bins in the first time window. The symbol $n c$ represents the number of time bins in the second time window. A Gaussian algorithm can then be used to compare counts in the two adjacent windows, as shown in Equation (1).

$$
G=\frac{\frac{1}{n c} \sum_{j=i}^{i+n c} x_{j}-\frac{1}{n p} \sum_{j=i-n p}^{i-1} x_{j}}{\sqrt{\frac{s_{i}}{n c}+\frac{s_{j}}{n p}}}
$$

The symbol $s_{j}$ represents the standard deviation of counts in the first time window and the symbol $s_{i}$ represents the standard deviation of counts in the second time window.

To illustrate this morphing phenomenon, an example using the BioTechniques dataset is shown in Figures 2 and 3. Figure 2 shows how the documents are distributed over time, while normalized temporal profiles for multiple terms are shown in Figure 3. The profiles represent the number of documents at each time interval that contains the specific term. The number on the right side of the profile represents the maximum number of documents within the profile containing the specific term.

The purple circle identifies the time associated with the greatest decreasing emergence score, which may indicate a possible morphing candidate. The red circles identify the time associated with the greatest increasing emergence score occurring close to the time indicated by the purple circle, which may identify possible transition terms. In fact, the results shown in Figure 3 do actually indicate that the usage of the term polymerase chain reaction is replaced by the abbreviation pcr. 


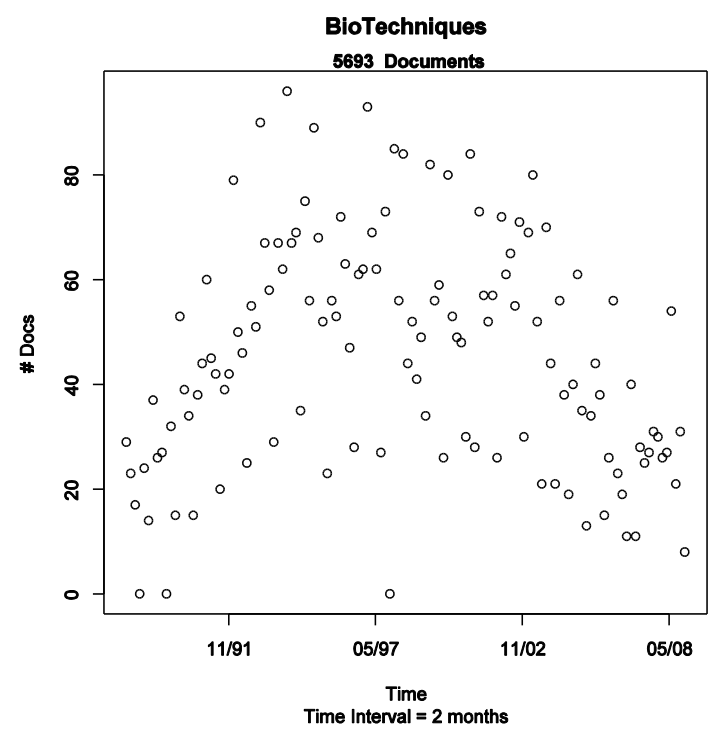

Figure 2 Temporal distribution of documents within the BioTechniques dataset, using two month intervals.

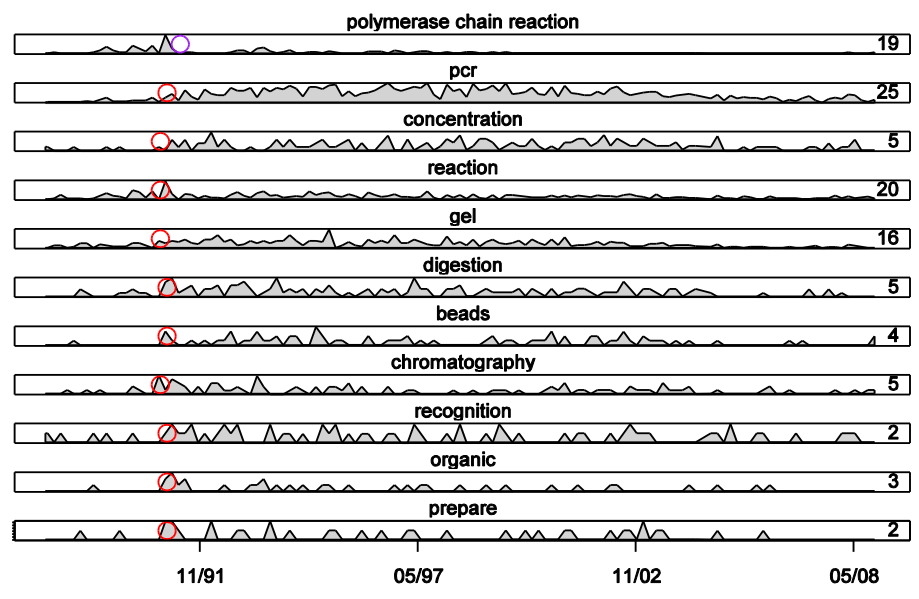

Figure 3 Temporal profiles of document frequencies for the term polymerase chain reaction, along with terms with increasing occurrences close to the same time (BioTechniques dataset).

While temporal analysis of term occurrences can identify temporally related events, additional insight may be gained into surprising combinations of terms by applying a similar analysis to term co-occurrence information.

\section{Temporal Analysis of Term Document Co-occurrences}

Evaluating the change over time of term-pair co-occurrences yields insight to whether terms are being used differently. Because it is computationally intensive to calculate all term-document co-occurrences, in practice this is reduced to calculating term document co-occurrences in relation to a particular context, which may be set as a root term of interest. In this case, all co-occurrences with the root term of interest are accumulated.

\section{Surprise and Emergence}

The Surprise and Emergence algorithms can be applied to term-pair co-occurrences in order to identify term transitions. Surprising term co-occurrences may aid identification of new combinations. Emergence of term co-occurrences may aid identification of changing terminology, vocabulary specialization, or novel technology combinations that persist.

We expect that the phenomenon illustrated in Figure 3 occurs much more frequently, albeit in less obvious cases, and to be an indicator of terminology specialization and diversification, which can be an indicator of new technology applications. To help strengthen the "signal" for these transition points, we have added algorithm heuristics for measuring the co-occurrence of terms within documents. The term co-occurrence score can be calculated during times where a temporal nexus exists among terms that are emerging as shown by red circles in Figure 3, while other terms are declining as represented by the purple 
circle in the figure. The co-occurrence heuristic will help validate the transition points between related terms and help filter out purely coincidental term co-occurrences.

An example of the morphing phenomenon as identified using term-pair co-occurrences is shown in Figure 4 and Table 1. In this figure, the top profile for each plot shows the number of documents within each time bin that contains the term polymerase chain reaction, scaled $(0,1)$. The purple circle identifies the time when the decreasing emergence score is maximum. In the right plot, the remaining profiles show the number of documents containing the specific term (e.g., chain, pcr, product), scaled $(0,1)$. The maximum number of documents within a time interval for each term is shown on the right side of each profile. In the left plot, the profiles below the top profile show the number of documents that contain the term polymerase chain reaction and the specific term (i.e., term-pair co-occurrence), scaled $(0,1)$. The number on the right side of each of these profiles represents the maximum term-pair co-occurrences within a time interval. The order of the term profiles plotted below the polymerase chain reaction profile is determined based on the proportion of the maximum term-pair co-occurrence (identified by the red circle) to the total number of documents containing the specific term within the same time interval (as shown in Table 1).

From Figure 4, we can see that the number of documents containing the polymerase chain reaction term in the BioTechniques dataset decreases rapidly in 1991, while other terms (e.g., pcr, amplification) see increasing document occurrences. The goal of our research is to automatically identify those transitioning terms and show the results to a subject matter expert (SME). From the results shown in Figure 4 and Table 1, an SME could easily identify the transition (morphing) of the term polymerase chain reaction to $p c r$.

described

Figure 4 Temporal profiles of term-pair co-occurrences (left plot) and document frequencies (right plot) for the term polymerase chain reaction and related terms (BioTechniques dataset). 
Table 1 Term-pair co-occurrences of polymerase chain reaction and related terms in late 1991.

\begin{tabular}{|l|c|c|c|}
\hline \multicolumn{1}{|c|}{$\begin{array}{c}\text { Term } \\
\text { chain }\end{array}$} & $\begin{array}{c}\text { Max. Term-Pair } \\
\text { Co-occurrences }\end{array}$ & $\begin{array}{c}\text { Number Term } \\
\text { Documents }\end{array}$ & Proportion \\
\hline pcr & 19 & 19 & 1.00 \\
\hline product & 6 & 6 & 1.00 \\
\hline reaction & 5 & 5 & 1.00 \\
\hline polymerase & 19 & 20 & 0.95 \\
\hline amplification & 19 & 21 & 0.91 \\
\hline described & 8 & 10 & 0.80 \\
\hline rapid & 5 & 7 & 0.71 \\
\hline method & 9 & 13 & 0.69 \\
\hline dna & 8 & 16 & 0.50 \\
\hline
\end{tabular}

\section{Ranking Terms by Variance Over Time}

Ranking terms by the variance of their document co-occurrences with a root term is an effective means of identifying those terms whose usage with the root term changes significantly over time. Within a defined document context, variance of term document co-occurrences signals change in that term's association with the document context. In the table below, document co-occurrence counts of individual terms with the root term polymerase chain reaction are shown. Terms are sorted by the sum of their document co-occurrences with polymerase chain reaction. Referring to Table 2 , we can see that pcr cooccurs in 73 documents with polymerase chain reaction in the BioTechniques dataset.

Table 2 Terms sorted by sum of document co-occurrences with polymerase chain reaction.

\begin{tabular}{|c|c|c|c|c|c|c|c|c|c|c|c|c|c|c|c|c|c|c|c|c|c|c|}
\hline \multirow[b]{2}{*}{ term } & \multicolumn{21}{|c|}{ count of document co-occurrences with "polymerase chain reaction" by year } & \multirow[b]{2}{*}{$\underline{\text { sum }}$} \\
\hline & $\begin{array}{l}\infty \\
\infty \\
\sigma \\
-1\end{array}$ & $\begin{array}{l}\text { م) } \\
\infty \\
\text { مे }\end{array}$ & 요 & ન્ન & ๙ু & ન్ & নু & 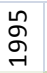 & $\begin{array}{l}\text { مू } \\
\text { ने }\end{array}$ & बू & م & જ & ᄋㅇㅇ & 궁 & プ & $\begin{array}{l}m \\
\text { O̊ } \\
\text { ㄱ. }\end{array}$ & 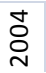 & 号 & ర̊ & 옹 & $\begin{array}{l}\infty \\
\stackrel{\bigcirc}{\bigcirc} \\
\text { ㄱ. }\end{array}$ & \\
\hline polymerase chain reaction & 2 & 16 & 28 & 25 & 5 & 16 & 5 & 4 & 10 & 6 & 4 & 3 & 0 & 0 & 0 & 0 & 0 & 0 & 0 & 0 & 2 & 126 \\
\hline polymerase & 2 & 16 & 28 & 25 & 5 & 16 & 5 & 4 & 10 & 6 & 4 & 3 & 0 & 0 & 0 & 0 & 0 & 0 & 0 & 0 & 2 & 126 \\
\hline reaction & 2 & 16 & 28 & 25 & 5 & 16 & 5 & 4 & 10 & 6 & 4 & 3 & 0 & 0 & 0 & 0 & 0 & 0 & 0 & 0 & 2 & 126 \\
\hline pcr & 0 & 10 & 10 & 8 & 5 & 14 & 4 & 2 & 8 & 5 & 3 & 2 & 0 & 0 & 0 & 0 & 0 & 0 & 0 & 0 & 2 & 73 \\
\hline dna & 1 & 9 & 15 & 15 & 4 & 9 & 4 & 2 & 3 & 4 & 2 & 1 & 0 & 0 & 0 & 0 & 0 & 0 & 0 & 0 & 1 & 70 \\
\hline method & 0 & 4 & 13 & 11 & 4 & 10 & 2 & 0 & 6 & 3 & 3 & 0 & 0 & 0 & 0 & 0 & 0 & 0 & 0 & 0 & 2 & 58 \\
\hline amplificat & 1 & 7 & 11 & 10 & 3 & 7 & 1 & 1 & 4 & 4 & 2 & 1 & 0 & 0 & 0 & 0 & 0 & 0 & 0 & 0 & 1 & 53 \\
\hline primers & 0 & 6 & 7 & 7 & 3 & 7 & 2 & 1 & 5 & 2 & 0 & 1 & 0 & 0 & 0 & 0 & 0 & 0 & 0 & 0 & 0 & 41 \\
\hline procedure & 0 & 5 & 9 & 5 & 1 & 6 & 3 & 1 & 3 & 1 & 0 & 1 & 0 & 0 & 0 & 0 & 0 & 0 & 0 & 0 & 0 & 35 \\
\hline products & 0 & 3 & 7 & 4 & 0 & 5 & 4 & 0 & 5 & 3 & 1 & 2 & 0 & 0 & 0 & 0 & 0 & 0 & 0 & 0 & 0 & 34 \\
\hline analysis & 0 & 9 & 4 & 5 & 2 & 5 & 1 & 0 & 5 & 1 & 2 & 0 & 0 & 0 & 0 & 0 & 0 & 0 & 0 & 0 & 0 & 34 \\
\hline polymerase chain reaction pcr & 0 & 10 & 5 & 3 & 2 & 8 & 0 & 0 & 1 & 1 & 1 & 1 & 0 & 0 & 0 & 0 & 0 & 0 & 0 & 0 & 1 & 33 \\
\hline specific & 0 & 4 & 7 & 7 & 2 & 4 & 2 & 2 & 2 & 0 & 0 & 1 & 0 & 0 & 0 & 0 & 0 & 0 & 0 & 0 & 2 & 33 \\
\hline sequence & 0 & 6 & 6 & 6 & 3 & 2 & 2 & 0 & 1 & 2 & 1 & 1 & 0 & 0 & 0 & 0 & 0 & 0 & 0 & 0 & 0 & 30 \\
\hline gene & 0 & 5 & 6 & 3 & 2 & 4 & 0 & 0 & 6 & 2 & 0 & 0 & 0 & 0 & 0 & 0 & 0 & 0 & 0 & 0 & 1 & 29 \\
\hline
\end{tabular}

Sorting by sum enables easy identification of terms that occur the most frequently within the given context, but it provides little information on terms whose usage with the root term changes over time. Listed in Table 3 below are terms sorted by the standard deviation of their document co-occurrences over 
the years with the root term. While useful, the results are dominated by the temporal distribution of the root term, polymerase chain reaction.

Table 3 Terms sorted by standard deviation of yearly document co-occurrences with polymerase chain reaction.

\begin{tabular}{|c|c|c|c|c|c|c|c|c|c|c|c|c|c|c|c|c|c|c|c|c|c|c|}
\hline \multirow[b]{2}{*}{$\underline{\text { term }}$} & \multicolumn{21}{|c|}{ count of document co-occurrences with "polymerase chain reaction" by year } & \multirow[b]{2}{*}{$\begin{array}{l}\text { std. } \\
\text { dev }\end{array}$} \\
\hline & $\begin{array}{l}\infty \\
\stackrel{\infty}{-} \\
\stackrel{-}{-1}\end{array}$ & $\begin{array}{l}\text { న } \\
\text { య్ન }\end{array}$ & 음 & ન્ન & న్ & ต్ & ন্ন & ๙ூ & 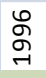 & बે & $\begin{array}{l}\infty \\
\text { જ̆ }\end{array}$ & ब్ & 음 & 공 & 응 & @̊ & ১্ঠ & 옹 & ○ & 옹 & 只 & \\
\hline polymerase & 2 & 16 & 28 & 25 & 5 & 16 & 5 & 4 & 10 & 6 & 4 & 3 & 0 & 0 & 0 & 0 & 0 & 0 & 0 & 0 & 2 & 8.37 \\
\hline reaction & 2 & 16 & 28 & 25 & 5 & 16 & 5 & 4 & 10 & 6 & 4 & 3 & 0 & 0 & 0 & 0 & 0 & 0 & 0 & 0 & 2 & 8.37 \\
\hline dna & 1 & 9 & 15 & 15 & 4 & 9 & 4 & 2 & 3 & 4 & 2 & 1 & 0 & 0 & 0 & 0 & 0 & 0 & 0 & 0 & 1 & 4.73 \\
\hline method & 0 & 4 & 13 & 11 & 4 & 10 & 2 & 0 & 6 & 3 & 3 & 0 & 0 & 0 & 0 & 0 & 0 & 0 & 0 & 0 & 2 & 4.02 \\
\hline amplification & 1 & 7 & 11 & 10 & 3 & 7 & 1 & 1 & 4 & 4 & 2 & 1 & 0 & 0 & 0 & 0 & 0 & 0 & 0 & 0 & 1 & 3.43 \\
\hline polymerase chain reaction $\mathrm{pcr}$ & 0 & 10 & 5 & 3 & 2 & 8 & 0 & 0 & 1 & 1 & 1 & 1 & 0 & 0 & 0 & 0 & 0 & 0 & 0 & 0 & 1 & 2.79 \\
\hline primers & 0 & 6 & 7 & 7 & 3 & 7 & 2 & 1 & 5 & 2 & 0 & 1 & 0 & 0 & 0 & 0 & 0 & 0 & 0 & 0 & 0 & 2.71 \\
\hline procedure & 0 & 5 & 9 & 5 & 1 & 6 & 3 & 1 & 3 & 1 & 0 & 1 & 0 & 0 & 0 & 0 & 0 & 0 & 0 & 0 & 0 & 2.56 \\
\hline products & 0 & 3 & 7 & 4 & 0 & 5 & 4 & 0 & 5 & 3 & 1 & 2 & 0 & 0 & 0 & 0 & 0 & 0 & 0 & 0 & 0 & 2.22 \\
\hline gene & 0 & 5 & 6 & 3 & 2 & 4 & 0 & 0 & 6 & 2 & 0 & 0 & 0 & 0 & 0 & 0 & 0 & 0 & 0 & 0 & 1 & 2.13 \\
\hline
\end{tabular}

The temporal variance of polymerase chain reaction can be factored out of each term's standard deviation by calculating the relative proportion of each term's yearly document co-occurrences with polymerase chain reaction. Table 4 lists terms sorted by the standard deviation of their proportion of yearly document co-occurrences relative to the number of documents each year in which polymerase chain reaction occurs. We can see that $\boldsymbol{r t}$, rt pcr, and reverse transcription (the term that the abbreviation $\boldsymbol{r t}$ refers to) occur with greatest frequency with polymerase chain reaction from 1994 to 1998, the years that RT-PCR first came into use. This relationship was not evident when sorting by sum or standard deviation of raw term document co-occurrences as shown in Tables 2 and 3.

Table 4 Terms sorted by standard deviation of yearly relative proportion with polymerase chain reaction.

\begin{tabular}{|c|c|c|c|c|c|c|c|c|c|c|c|c|c|c|c|c|c|c|c|c|c|c|}
\hline \multirow[b]{2}{*}{$\underline{\text { term }}$} & \multicolumn{21}{|c|}{ relative proportion of doc co-occurrences with "polymerase chain reaction" by year } & \multirow[b]{2}{*}{$\begin{array}{l}\text { std. } \\
\text { dev. }\end{array}$} \\
\hline & $\begin{array}{l}\infty \\
\infty \\
\stackrel{-}{-}\end{array}$ & $\begin{array}{l}\stackrel{\circ}{\infty} \\
\stackrel{\infty}{न}\end{array}$ & 욤 & ન્' & مू & 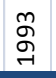 & ন & ڤొ & ๙ & م્ & 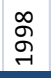 & જ & ঃ & 공 & 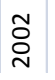 & $\stackrel{m}{\stackrel{\nu}{~}}$ & ঠ্ঠ & ำ & ○ & 윰 & 只 & \\
\hline polymerase chain reaction & 1.00 & 1.00 & 1.00 & 1.00 & 1.00 & 1.00 & 1.00 & 1.00 & 1.00 & 1.00 & 1.00 & 1.00 & 0.000 & 0.00 & 0.00 & 0.00 & 0.00 & 0.00 & 0.00 & 0.00 & 1.00 & 0.5 \\
\hline reaction & 1.00 & 1.00 & 1.00 & 1.00 & 1.00 & 1.00 & 1.00 & 1.00 & 1.00 & 1.00 & 1.00 & 1.00 & 0.000 & 0.00 & 0.00 & 0.00 & 0.00 & 0.00 & 0.00 & 0.00 & 1.00 & 0.5 \\
\hline polymerase & 1.00 & 1.00 & 1.00 & 1.00 & 1.00 & 1.00 & 1.00 & 1.00 & 1.00 & 1.00 & 1.00 & 1.00 & 0.000 & 0.00 & 0.00 & 0.00 & 0.00 & 0.00 & 0.00 & 0.00 & 1.00 & 0.5 \\
\hline pcr & 0.33 & 0.65 & 0.38 & 0.35 & 1.00 & 0.88 & 0.83 & 0.60 & 0.82 & 20.86 & 0.80 & 0.75 & 0.000 & 0.00 & 0.00 & 0.00 & 0.00 & 0.00 & 0.00 & 0.00 & 1.00 & 0.41 \\
\hline method & 0.33 & 0.29 & 0.48 & 0.46 & 0.83 & 0.65 & 0.50 & 0.20 & 0.64 & 40.57 & 0.80 & 0.25 & 0.000 & 0.00 & 0.00 & 0.00 & 0.00 & 0.00 & 0.00 & 0.00 & 1.00 & 0.34 \\
\hline dna & 0.67 & 0.59 & 0.55 & 0.62 & 0.83 & 0.59 & 0.83 & 0.60 & 0.36 & 60.71 & 0.60 & 0.50 & 0.000 & 0.00 & 0.00 & 0.00 & 0.00 & 0.00 & 0.00 & 0.00 & 0.67 & 70.33 \\
\hline $\mathrm{rt}$ & 0.33 & 0.06 & 0.07 & 0.04 & 0.17 & 0.06 & 0.67 & 0.40 & 0.73 & 30.71 & 0.80 & 0.25 & 0.000 & 0.00 & 0.00 & 0.00 & 0.00 & 0.00 & 0.00 & 0.00 & 0.67 & 70.3 \\
\hline rt pcr & 0.33 & 0.06 & 0.07 & 0.04 & 0.17 & 0.06 & 0.67 & 0.40 & 0.73 & 30.57 & 0.80 & 0.25 & 0.000 & 0.00 & 0.00 & 0.00 & 0.00 & 0.00 & 0.00 & 0.00 & 0.67 & 70.29 \\
\hline reverse transcription & 0.33 & 0.12 & 0.10 & 0.08 & 0.17 & 0.12 & 0.67 & 0.60 & 0.73 & 30.71 & 0.80 & 0.25 & 0.000 & 0.00 & 0.00 & 0.00 & 0.00 & 0.00 & 0.00 & 0.00 & 0.33 & 30.29 \\
\hline transcription & 0.33 & 0.12 & 0.14 & 0.08 & 0.33 & 0.12 & 0.67 & 0.60 & 0.73 & 0.71 & 0.80 & 0.25 & 0.000 & 0.00 & 0.00 & 0.00 & 0.00 & 0.00 & 0.00 & 0.00 & 0.33 & 30.29 \\
\hline amplification & 0.67 & 0.47 & 0.41 & 0.42 & 0.67 & 0.47 & 0.33 & 0.40 & 0.45 & 50.71 & 0.60 & 0.50 & 0.000 & 0.00 & 0.00 & 0.00 & 0.00 & 0.00 & 0.00 & 0.00 & 0.67 & 70.27 \\
\hline specific & 0.33 & 0.29 & 0.28 & 0.31 & 0.50 & 0.29 & 0.50 & 0.60 & 0.27 & 70.14 & 0.20 & 0.50 & 0.000 & 0.00 & 0.00 & 0.00 & 0.00 & 0.00 & 0.00 & 0.00 & 1.00 & 0.27 \\
\hline products & 0.33 & 0.24 & 0.28 & 0.19 & 0.17 & 0.35 & 0.83 & 0.20 & 0.55 & 50.57 & 0.40 & 0.75 & 0.000 & 0.00 & 0.00 & 0.00 & 0.00 & 0.00 & 0.00 & 0.00 & 0.33 & 30.26 \\
\hline detection & 0.33 & 0.12 & 0.10 & 0.15 & 0.33 & 0.41 & 0.50 & 0.40 & 0.45 & 50.43 & 0.40 & 0.25 & 0.000 & 0.00 & 0.00 & 0.00 & 0.00 & 0.00 & 0.00 & 0.00 & 1.00 & 0.26 \\
\hline polymerase chain reaction pcr & 0.33 & 0.65 & 0.21 & 0.15 & 0.50 & 0.53 & 0.17 & 0.20 & 0.18 & 80.29 & 0.40 & 0.50 & 0.000 & 0.00 & 0.00 & 0.00 & 0.00 & 0.00 & 0.00 & 0.00 & 0.67 & 70.24 \\
\hline
\end{tabular}


Because Tables 2-4 were calculated with the document context set with the root term polymerase chain reaction, only those documents containing that term factor into the rankings. Notably, polymerase chain reaction did not occur in any documents for the years 2000 - 2007, making it difficult to assess whether related terms such as reverse transcription or $\boldsymbol{r t}$ pcr continued to be used or disappeared as well. We can get a better picture of terminology transitions by setting the context to documents containing the more frequent term pcr. Table 5 lists terms sorted by the standard deviation of their proportion of yearly document co-occurrences relative to the number of documents each year in which pcr occurs.

Table 5 Terms sorted by standard deviation of yearly relative proportion with $\boldsymbol{p c r}$.

\begin{tabular}{|c|c|c|c|c|c|c|c|c|c|c|c|c|c|c|c|c|c|c|c|c|c|c|}
\hline \multirow[b]{2}{*}{$\underline{\text { term }}$} & \multicolumn{21}{|c|}{ relative proportion of doc co-occurrences with "pcr" by year } & \multirow[b]{2}{*}{$\begin{array}{l}\text { std. } \\
\text { dev. }\end{array}$} \\
\hline & $\begin{array}{l}\infty \\
\infty \\
\stackrel{-}{్}\end{array}$ & $\begin{array}{l}\sigma \\
\infty \\
\text { م్ન }\end{array}$ & 욤 & ન્- & ్్ㄱ & 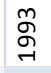 & ஓ & คั & $\begin{array}{l}\text { ஜ } \\
\text { ్ }\end{array}$ & م્ & 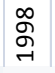 & ஓ & ○̊ํㅁ & ర্ & 응 & mo & ১্ঠ & 옹 & $\begin{array}{l}\text { ஜ } \\
\text { ঃ }\end{array}$ & 응 & 串 & \\
\hline polymerase chain reaction & 0.00 & 0.79 & 0.73 & 0.19 & 0.07 & 0.15 & 0.04 & 0.03 & 0.08 & 0.06 & 0.04 & 0.03 & 0.01 & 0.01 & 10.01 & 0.01 & 0.02 & 0.02 & 0.03 & 0.03 & 30.10 & 0.22 \\
\hline pcr & 0.00 & 1.00 & 1.00 & 1.00 & 1.00 & 1.00 & 1.00 & 1.00 & 1.00 & 1.00 & 1.00 & 1.00 & 1.00 & 1.00 & 1.00 & 1.00 & 1.00 & 1.00 & 1.00 & 1.00 & 1.00 & 0.22 \\
\hline polymerase & 0.00 & 0.79 & 0.73 & 0.23 & 0.15 & 0.19 & 0.15 & 0.07 & 0.15 & 0.15 & 0.10 & 0.06 & 0.06 & 0.09 & 0.08 & 0.09 & 0.02 & 0.05 & 0.03 & 0.03 & 30.16 & 0.21 \\
\hline reaction & 0.00 & 0.79 & 0.73 & 0.32 & 0.19 & 0.24 & 0.12 & 0.15 & 0.16 & 0.13 & 0.13 & 0.10 & 0.12 & 0.07 & 70.13 & 0.09 & 0.09 & 0.12 & 0.13 & 0.13 & 30.26 & 0.20 \\
\hline polymerase chain reaction pcr & 0.00 & 0.79 & 0.40 & 0.09 & 0.03 & 0.09 & 0.01 & 0.01 & 0.02 & 0.02 & 0.02 & 0.02 & 0.01 & 0.01 & 10.01 & 0.01 & 0.02 & 0.02 & 0.03 & 0.03 & 30.06 & 0.18 \\
\hline dna & 0.00 & 0.71 & 0.53 & 0.53 & 0.66 & 0.56 & 0.52 & 0.41 & 0.41 & 0.35 & 0.49 & 0.46 & 0.49 & 0.53 & 0.52 & 0.51 & 0.46 & 0.49 & 0.60 & 0.53 & 30.71 & 0.15 \\
\hline real time & 0.00 & 0.07 & 0.07 & 0.02 & 0.01 & 0.02 & 0.01 & 0.01 & 0.02 & 0.01 & 0.03 & 0.06 & 0.07 & 0.11 & 10.18 & 0.20 & 0.35 & 0.34 & 0.33 & 0.30 & 0.35 & 0.13 \\
\hline time & 0.00 & 0.14 & 0.20 & 0.11 & 0.01 & 0.08 & 0.06 & 0.04 & 0.05 & 0.07 & 0.09 & 0.10 & 0.16 & 0.16 & 50.29 & 0.24 & 0.37 & 0.34 & 0.33 & 0.33 & 30.45 & 0.13 \\
\hline gene & 0.00 & 0.50 & 0.27 & 0.17 & 0.27 & 0.22 & 0.17 & 0.19 & 0.18 & 0.17 & 0.23 & 0.23 & 0.29 & 0.29 & 9.44 & 0.40 & 0.44 & 0.34 & 0.50 & 0.33 & 30.23 & 0.13 \\
\hline amplification & 0.00 & 0.50 & 0.53 & 0.47 & 0.35 & 0.47 & 0.26 & 0.25 & 0.28 & 0.20 & 0.32 & 0.26 & 0.33 & 0.29 & 0.32 & 0.44 & 0.22 & 0.20 & 0.37 & 0.37 & 70.32 & 0.12 \\
\hline method & 0.00 & 0.43 & 0.40 & 0.49 & 0.52 & 0.37 & 0.33 & 0.30 & 0.33 & 0.31 & 0.38 & 0.40 & 0.40 & 0.43 & 30.40 & 0.49 & 0.35 & 0.46 & 0.50 & 0.43 & 30.65 & 0.12 \\
\hline sequencing & 0.00 & 0.57 & 0.33 & 0.21 & 0.19 & 0.18 & 0.20 & 0.15 & 0.08 & 0.08 & 0.12 & 0.10 & 0.09 & 0.09 & 0.10 & 0.09 & 0.09 & 0.15 & 0.17 & 0.23 & 30.19 & 0.12 \\
\hline analysis & 0.00 & 0.50 & 0.20 & 0.26 & 0.23 & 0.22 & 0.19 & 0.21 & 0.23 & 0.19 & 0.22 & 0.24 & 0.26 & 0.34 & 0.42 & 0.33 & 0.39 & 0.41 & 0.30 & 0.47 & 70.32 & 0.11 \\
\hline real time pcr & 0.00 & 0.07 & 0.07 & 0.02 & 0.01 & 0.01 & 0.01 & 0.01 & 0.01 & 0.01 & 0.01 & 0.02 & 0.03 & 0.07 & 70.14 & 0.10 & 0.22 & 0.29 & 0.27 & 0.20 & 0.23 & 0.10 \\
\hline sequence & 0.00 & 0.50 & 0.33 & 0.30 & 0.20 & 0.19 & 0.20 & 0.15 & 0.12 & 0.16 & 0.16 & 0.22 & 0.13 & 0.27 & 70.18 & 0.33 & 0.20 & 0.24 & 0.23 & 0.13 & 30.26 & 0.10 \\
\hline
\end{tabular}

The term pcr is initially used in 1989. The term polymerase chain reaction occurs relatively frequently with pcr in 1989 and 1990 but then sharply drops off in the following years. Additionally, the terms real time, time, and real time pcr gradually increase in co-occurrence with pcr after 2000, as instruments were employed to replace the manual detection assay with quantitative monitoring of each step in the 25- to 40-step automated amplification reaction, enabling simultaneous detection and calculation of the number of starting molecules. Also, in the context of co-occurrence analysis, analysis of the term pcr enables identification of later morphing terms (real time pcr) that the initial term polymerase chain reaction did not identify.

Ranking terms of interest by the variance of their temporal document occurrences for a given context can help users identify when and to what degree term usage changes within the context. The effectiveness of the ranking is dependent on the validity and accuracy of the measurement of variance. Standard deviation in this case may be affected by the sizes of the time intervals as well as their boundaries. While Tables 4 and 5 show that calculating variance across yearly time intervals can be applied to journal publications, such as BioTechniques, a measure of variance that spans the entire time range without defined time intervals may be more broadly applicable to a wider range of datasets. 


\subsection{Analysis of Term Associations}

A particularly interesting challenge for detecting transitions from the use of one term to another term is found when those terms co-occur in only a few, or zero, documents. If we consider that a rapid transition such as the replacement of one term with another, or the combination of previously unrelated terms, may be reflected within very few documents, then methods that depend solely on document associations may miss these transitions. Evaluating term feature associations provides complementary information to term document associations. A term's feature associations comprise the complete set of the term's association with individual features, which are calculated as the sum of the term's occurrences within documents that contain the feature (typically another term). Terms have similar feature associations when they predominantly co-occur with the same terms and can therefore be expected to occur within the same documents. Alternatively, terms that have dissimilar feature associations do not predominantly co-occur with the same terms and can therefore be expected to not occur within the same documents. Identifying terms whose usage is unexpectedly increasing or decreasing with a root term is a matter of calculating the difference of the similarity between feature associations for each term and the root term with the similarity between document associations for each term and the root term.

Figure 5 presents a conceptual model and topic of future work for plotting the similarity of a term's document associations and feature associations to those of a given root term. Terms that are similarly associated with the same features as the root term can be expected to co-occur within the same documents (upper right in the plot) as the root term. Alternatively, if terms have dissimilar feature associations, then they can be expected to not co-occur within the same documents (lower left in the plot) as the root term. A term that has dissimilar feature and document associations with the root term is of particular interest and will be plotted off of the main diagonal. Terms that have similar features to the root term but occur in different documents will appear in the red cells in the upper left area of the plot, indicating that they are related by other terms but not necessarily by context of usage. Terms that have dissimilar features to the root term but occur in the same documents will appear in the blue cells in the lower right area of the plot, indicating an unusual or new combination of predominantly unrelated terms.

We have reduced to practice the comparison of terms' feature associations with their document associations over time in order to identify trends as well as unexpected replacements and combinations of terms within distinct time intervals. We discuss several results of applying this analytic approach in the following section. 


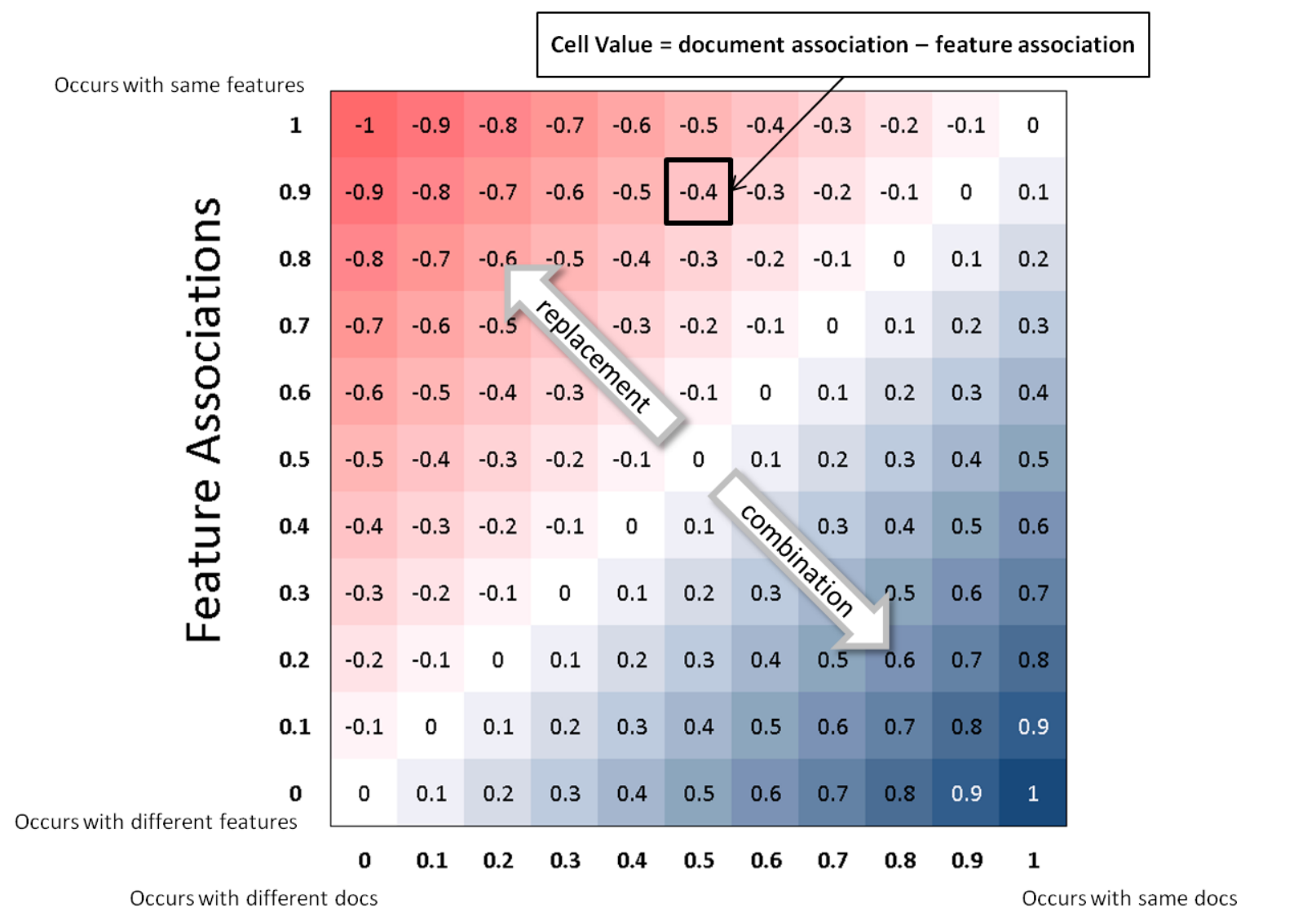

\section{Document Associations}

Figure 5 The dimensions of feature association and document association, with representative cells color encoded by the difference of document association and feature association at their respective location in the context of a defined root term.

\subsection{Temporal Analysis of Term Associations}

Because global statistics across the entire time range can wipe out indications of temporally focused transitions, we explored methods for quantifying how dissimilar a term's document associations are from its feature associations within time intervals. Doing so should enable a user to identify points in time or broad trends where these two associations differ, indicating important transitions in terminology.

Each term's feature associations and document associations are calculated within distinct time intervals and their similarity, as the Czekanowski coefficient, with the root term's associations is calculated. This provides for each year a similarity measure of each term's document associations to that of the defined root term, in this case polymerase chain reaction (shown in Table 6) or pcr, as well as a similarity measure of each term's feature association to that of the defined root term (shown in Table 7 for polymerase chain reaction). 
Table 6 Similarity of terms' document associations by year to the document associations for the term polymerase chain reaction.

\begin{tabular}{|c|c|c|c|c|c|c|c|c|c|c|c|c|c|c|c|c|c|c|c|c|c|c|}
\hline & $\begin{array}{l}\infty \\
\infty \\
\infty \\
\sim\end{array}$ & 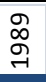 & 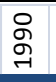 & ન્ન & ने & જે & హ్ & ڤึ & ڤ̆ & बे & 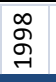 & $\begin{array}{l}\text { बे } \\
\text { ब्न }\end{array}$ & ○ ํํ & ㄱㅇㅇ & 응 & 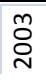 & ঠ্ণ & 옹 & ○̊ & 응 & $\begin{array}{l}\infty \\
\text { ○ } \\
\text { ㄱ }\end{array}$ & $\begin{array}{l}\text { std. } \\
\text { dev. }\end{array}$ \\
\hline react & 0.3 & 0.8 & 0.9 & 0.8 & 0.3 & 0.6 & 0.2 & 0.2 & 0.4 & 0.4 & 0.2 & 0.3 & 0.0 & 0.0 & 0.0 & 0.0 & 0.0 & 0.0 & 0.0 & 0.0 & 0.3 & 0.3 \\
\hline polymeras & 0.5 & 0.7 & 0.9 & 0.8 & 0.3 & 0.7 & 0.2 & 0.2 & 0.4 & 0.3 & 0.2 & 0.4 & 0.0 & 0.0 & 0.0 & 0.0 & 0.0 & 0.0 & 0.0 & 0.0 & 0.4 & 0.3 \\
\hline polymerase chain reaction pcr & 0.0 & 0.7 & 0.2 & 0.2 & 0.6 & 0.6 & 0.0 & 0.0 & 0.2 & 0.3 & 0.4 & 0.5 & 0.0 & 0.0 & 0.0 & 0.0 & 0.0 & 0.0 & 0.0 & 0.0 & 0.7 & 0.3 \\
\hline amplification & 0.7 & 0.4 & 0.4 & 0.2 & 0.1 & 0.1 & 0.0 & 0.0 & 0.1 & 0.1 & 0.0 & 0.0 & 0.0 & 0.0 & 0.0 & 0.0 & 0.0 & 0.0 & 0.0 & 0.0 & 0.1 & 0.2 \\
\hline rever & 0.0 & 0.1 & 0.1 & 0.1 & 0.0 & 0.0 & 0.3 & 0.2 & 0.1 & 0.0 & 0.2 & 0.0 & 0.0 & 0.0 & 0.0 & 0.0 & 0.0 & 0.0 & 0.0 & 0.0 & 0.7 & 0.2 \\
\hline reverse & 0.0 & 0.1 & 0.1 & 0.1 & 0.0 & 0.1 & 0.3 & 0.3 & 0.5 & 0.4 & 0.3 & 0.0 & 0.0 & 0.0 & 0.0 & 0.0 & 0.0 & 0.0 & 0.0 & 0.0 & 0.0 & 0.2 \\
\hline dna amplification & 0.7 & 0.0 & 0.0 & 0.2 & 0.0 & 0.1 & 0.0 & 0.0 & 0.0 & 0.2 & 0.3 & 0.0 & 0.0 & 0.0 & 0.0 & 0.0 & 0.0 & 0.0 & 0.0 & 0.0 & 0.0 & 0.2 \\
\hline cdna & 0.0 & 0.0 & 0.1 & 0.0 & 0.0 & 0.0 & 0.0 & 0.7 & 0.0 & 0.0 & 0.2 & 0.0 & 0.0 & 0.0 & 0.0 & 0.0 & 0.0 & 0.0 & 0.0 & 0.0 & 0.0 & 0.2 \\
\hline pcr & 0.0 & 0.5 & 0.3 & 0.2 & 0.1 & 0.1 & 0.0 & 0.0 & 0.1 & 0.1 & 0.0 & 0.0 & 0.0 & 0.0 & 0.0 & 0.0 & 0.0 & 0.0 & 0.0 & 0.0 & 0.1 & 0.1 \\
\hline pcr technique & 0.0 & 0.1 & 0.1 & 0.0 & 0.0 & 0.0 & 0.3 & 0.0 & 0.0 & 0.3 & 0.4 & 0.0 & 0.0 & 0.0 & 0.0 & 0.0 & 0.0 & 0.0 & 0.0 & 0.0 & 0.0 & 0.1 \\
\hline
\end{tabular}

Table 6 shows the similarity of terms' yearly document associations to the polymerase chain reaction's document associations. As expected, the terms reaction and polymerase, words that are part of polymerase chain reaction, retain high coefficients for a period after 1988 (1989 - 1991); even though these terms occur in contexts other than polymerase chain reaction, they primarily occur with polymerase chain reaction. These coefficients decrease after 1991 to 1993 as reaction and polymerase are increasingly used in other contexts. Looking at terms that are not part of polymerase chain reaction, the document associations for amplification and dna amplification are very similar to those for polymerase chain reaction in 1988 but not in the following years, indicating that they were frequently used in the same documents as polymerase chain reaction in 1988 but infrequently from 1989 to 2008. This is expected because the first DNA amplification method was PCR, and after 1988 amplification and dna amplification would be expected to have high coefficients with pcr (what the language morphed to) instead of polymerase chain reaction (what the language morphed away from). A third point is the appearance of moderate coefficients for the term reverse transcription polymerase chain reaction rt pcr (truncated to reverse transcription polymerase in Table 6 and Table 8) in $1994-1998$, and cdna synthesis in 1995. This represents the period when PCR technology was first widely applied for analyzing RNA molecules, by coupling (a) the use of the enzyme reverse transcriptase to produce cDNA from RNA with (b) the DNA polymerase used to amplify DNA. This is also why there is a high coefficient for $\boldsymbol{c d n a}$ synthesis in 1995. These examples demonstrate that statistical analysis of term usage can be applied to automatically identify temporally related scientific developments described in journal publications.

Table 7 shows the similarity of terms' yearly feature associations to polymerase chain reaction's feature associations. We can see that the feature associations for pcr have the strongest overall similarity with the feature associations for the context, polymerase chain reaction. Referring back to Table 6, it is worth noting that pcr only has similar document associations with polymerase chain reaction in 1989, indicating that these two terms were not used often together in documents in the following years. 
Table 7 Similarity of terms' feature associations by year to the feature associations for the term polymerase chain reaction.

\begin{tabular}{|c|c|c|c|c|c|c|c|c|c|c|c|c|c|c|c|c|c|c|c|c|c|c|}
\hline \multicolumn{22}{|c|}{ czekanowski coefficient of feature associations by year in context of "polymerase chain reaction" } & \multirow[b]{2}{*}{$\begin{array}{l}\text { std. } \\
\text { dev. }\end{array}$} \\
\hline$\underline{\text { term }}$ & $\begin{array}{l}\infty \\
\infty \\
\infty \\
\sim\end{array}$ & 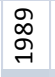 & 욤 & ન્ન & స్ & જે & ஓু & 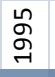 & જே & مू & م & જ & ᄋ & 옹 & 응 & O̊̊ & ষ্ঠ & 응 & ○̊ & 今̊ & $\begin{array}{l}\infty \\
\text { ○ } \\
\text { ○ }\end{array}$ & \\
\hline pcr & 0.0 & 0.2 & 0.2 & 0.5 & 0.6 & 0.7 & 0.6 & 0.6 & 0.6 & 0.6 & 0.6 & 0.6 & 0.6 & 0.6 & 0.6 & 0.5 & 0.5 & 0.4 & 0.4 & 0.4 & 0.4 & 0.2 \\
\hline rt & 0.0 & 0.0 & 0.0 & 0.0 & 0.0 & 0.0 & 0.2 & 0.3 & 0.4 & 0.2 & 0.4 & 0.3 & 0.2 & 0.1 & 0.3 & 0.1 & 0.2 & 0.1 & 0.1 & 0.1 & 0.1 & 0.1 \\
\hline amplification & 0.0 & 0.1 & 0.2 & 0.3 & 0.3 & 0.5 & 0.3 & 0.3 & 0.3 & 0.3 & 0.4 & 0.3 & 0.4 & 0.4 & 0.5 & 0.4 & 0.3 & 0.2 & 0.2 & 0.2 & 0.2 & 0.1 \\
\hline products & 0.0 & 0.1 & 0.2 & 0.2 & 0.2 & 0.4 & 0.4 & 0.3 & 0.3 & 0.3 & 0.4 & 0.3 & 0.3 & 0.3 & 0.3 & 0.2 & 0.2 & 0.2 & 0.1 & 0.1 & 0.1 & 0.1 \\
\hline polymerase & 0.0 & 0.3 & 0.4 & 0.3 & 0.3 & 0.3 & 0.3 & 0.2 & 0.3 & 0.2 & 0.2 & 0.1 & 0.1 & 0.2 & 0.2 & 0.1 & 0.1 & 0.1 & 0.0 & 0.0 & 0.1 & 0.1 \\
\hline rt pcr & 0.0 & 0.0 & 0.0 & 0.0 & 0.0 & 0.0 & 0.2 & 0.2 & 0.4 & 0.2 & 0.3 & 0.3 & 0.2 & 0.1 & 0.3 & 0.1 & 0.2 & 0.1 & 0.1 & 0.1 & 0.0 & 0.1 \\
\hline rna & 0.0 & 0.1 & 0.2 & 0.3 & 0.3 & 0.4 & 0.4 & 0.4 & 0.4 & 0.3 & 0.4 & 0.3 & 0.3 & 0.3 & 0.4 & 0.3 & 0.4 & 0.2 & 0.2 & 0.2 & 0.2 & 0.1 \\
\hline detection & 0.0 & 0.1 & 0.2 & 0.3 & 0.3 & 0.3 & 0.4 & 0.3 & 0.4 & 0.3 & 0.4 & 0.4 & 0.4 & 0.4 & 0.4 & 0.3 & 0.3 & 0.2 & 0.2 & 0.1 & 0.3 & 0.1 \\
\hline primers & 0.0 & 0.1 & 0.2 & 0.2 & 0.3 & 0.4 & 0.3 & 0.2 & 0.3 & 0.3 & 0.3 & 0.3 & 0.3 & 0.2 & 0.2 & 0.2 & 0.1 & 0.1 & 0.1 & 0.0 & 0.1 & 0.1 \\
\hline time & 0.0 & 0.1 & 0.2 & 0.2 & 0.1 & 0.2 & 0.2 & 0.1 & 0.1 & 0.1 & 0.3 & 0.2 & 0.3 & 0.2 & 0.3 & 0.3 & 0.4 & 0.2 & 0.2 & 0.2 & 0.3 & 0.1 \\
\hline primer & 0.0 & 0.1 & 0.1 & 0.1 & 0.3 & 0.2 & 0.3 & 0.3 & 0.3 & 0.3 & 0.3 & 0.2 & 0.2 & 0.2 & 0.3 & 0.2 & 0.1 & 0.2 & 0.1 & 0.1 & 0.1 & 0.1 \\
\hline
\end{tabular}

Calculating the difference between terms' document and feature similarity with polymerase chain reaction, shown in Table 8 enables identification of terms that have changed the most in their associations with polymerase chain reaction. A blue cell indicates a year in which a term's document associations with polymerase chain reaction are more similar than its feature associations with polymerase chain reaction, indicating that the term is co-occurring with polymerase chain reaction in more documents than expected. A red cell indicates a year in which a term's feature associations are more similar than its document associations with polymerase chain reaction, indicating that the term is cooccurring with polymerase chain reaction in fewer documents than expected. We can see that after 1990, pcr occurs in fewer documents with polymerase chain reaction than would be expected given the feature associations of the two terms, corresponding with the replacement vector in Figure 5. We can also see notable spikes in document association for dna amplification in 1988 and for cdna synthesis in 1995, corresponding with the combination vector in Figure 5, which are not evident in Table 2.

Table 8 Difference of similarities (Table 6-Table 7) for document associations and feature associations by year to the term polymerase chain reaction. difference of czekanowski coefficients (doc - feature) in context of "polymerase chain reaction"

\begin{tabular}{|c|c|c|c|c|c|c|c|c|c|c|c|c|c|c|c|c|c|c|c|c|c|c|}
\hline term & $\begin{array}{l}\infty \\
\infty \\
\stackrel{\circ}{\neg}\end{array}$ & $\begin{array}{l}\text { ஓ } \\
\text { ᄋે }\end{array}$ & 음 & ન્ન & જે & $\begin{array}{l}\stackrel{n}{\sigma} \\
\text { مे }\end{array}$ & すั & 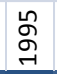 & $\begin{array}{l}\stackrel{\circ}{\Omega} \\
\text { ్ా }\end{array}$ & बे & $\begin{array}{l}\infty \\
\stackrel{్}{్}\end{array}$ & ஓ & ঃ & ס̊ & Õ & ֻ̊ & 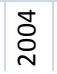 & 옹 & 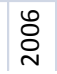 & 仓̊ & $\stackrel{\infty}{\circ}$ & $\frac{\text { std. }}{\text { dev. }}$ \\
\hline polymerase chain reaction & 1.0 & 0.8 & 0.7 & 0.7 & 0.9 & 0.8 & 0.9 & 1.0 & 0.9 & 0.9 & 1.0 & 1.0 & 0.0 & 0.0 & 0.0 & 0.0 & 0.0 & 0.0 & 0.0 & 0.0 & 1.0 & 0.5 \\
\hline amplification & 0.7 & 0.3 & 0.1 & -0.1 & -0.2 & -0.4 & -0.3 & -0.2 & -0.2 & -0.2 & -0.4 & -0.3 & -0.4 & -0.4 & -0.5 & -0.4 & -0.3 & -0.2 & -0.2 & -0.2 & -0.1 & 0.3 \\
\hline pcr & 0.0 & 0.3 & 0.1 & -0.3 & -0.6 & -0.5 & -0.6 & -0.6 & -0.6 & -0.6 & -0.6 & -0.6 & -0.6 & -0.6 & -0.6 & -0.5 & -0.5 & -0.4 & -0.4 & -0.4 & -0.3 & 0.2 \\
\hline polymerase chain reaction pcr & 0.0 & 0.5 & 0.1 & 0.1 & 0.5 & 0.6 & 0.0 & 0.0 & 0.2 & 0.3 & 0.4 & 0.5 & 0.0 & 0.0 & 0.0 & 0.0 & 0.0 & 0.0 & 0.0 & 0.0 & 0.7 & 0.2 \\
\hline polymerase & 0.5 & 0.5 & 0.5 & 0.5 & 0.0 & 0.4 & -0.1 & 0.0 & 0.1 & 0.1 & 0.0 & 0.3 & -0.1 & -0.2 & -0.2 & -0.1 & -0.1 & -0.1 & 0.0 & 0.0 & 0.4 & 0.2 \\
\hline reaction & 0.2 & 0.6 & 0.5 & 0.5 & 0.1 & 0.3 & 0.0 & -0.1 & 0.1 & 0.3 & 0.0 & 0.1 & -0.2 & -0.2 & -0.2 & -0.2 & -0.1 & -0.1 & -0.1 & -0.1 & 0.2 & 0.2 \\
\hline reverse transcription $p c$ & 0.0 & 0.0 & 0.0 & 0.0 & 0.0 & 0.0 & 0.5 & 0.4 & 0.7 & 0.5 & 0.4 & 0.0 & 0.0 & 0.0 & 0.0 & 0.0 & 0.0 & 0.0 & 0.0 & 0.0 & 0.0 & 0.2 \\
\hline reverse transcriptase & 0.0 & 0.1 & 0.0 & 0.0 & -0.1 & 0.0 & 0.3 & 0.2 & 0.1 & 0.0 & 0.1 & 0.0 & 0.0 & -0.1 & -0.1 & 0.0 & 0.0 & 0.0 & 0.0 & 0.0 & 0.7 & 0.2 \\
\hline dna amplification & 0.7 & 0.0 & 0.0 & 0.1 & 0.0 & 0.0 & 0.0 & 0.0 & 0.0 & 0.1 & 0.2 & 0.0 & 0.0 & 0.0 & 0.0 & 0.0 & 0.0 & 0.0 & 0.0 & 0.0 & 0.0 & 0.2 \\
\hline cdna synthesi & 0.0 & 0.0 & 0.0 & 0.0 & 0.0 & 0.0 & 0.0 & 0.7 & 0.0 & 0.0 & 0.2 & 0.0 & 0.0 & -0.1 & 0.0 & -0.1 & 0.0 & 0.0 & 0.0 & 0.0 & 0.0 & 0.1 \\
\hline primers & 0.0 & 0.3 & 0.1 & 0.1 & -0.2 & -0.2 & -0.2 & -0.2 & -0.1 & -0.2 & -0.3 & -0.2 & -0.3 & -0.2 & -0.2 & -0.2 & -0.1 & -0.1 & -0.1 & 0.0 & -0.1 & 0.1 \\
\hline products & 0.0 & 0.2 & 0.1 & 0.0 & -0.2 & -0.2 & -0.3 & -0.3 & -0.2 & -0.2 & -0.4 & -0.3 & -0.3 & -0.3 & -0.3 & -0.2 & -0.2 & -0.2 & -0.1 & -0.1 & -0.1 & 0.1 \\
\hline $\mathrm{rt}$ & 0.0 & 0.0 & 0.0 & 0.0 & 0.0 & 0.0 & -0.1 & -0.2 & -0.2 & 0.0 & -0.4 & -0.3 & -0.2 & -0.1 & -0.3 & -0.1 & -0.2 & -0.1 & -0.1 & -0.1 & 0.2 & 0.1 \\
\hline cdna & -0.1 & 0.1 & 0.0 & 0.0 & -0.1 & -0.2 & -0.3 & 0.1 & -0.2 & -0.2 & -0.2 & -0.3 & -0.2 & -0.4 & -0.3 & -0.3 & -0.3 & -0.2 & -0.2 & -0.1 & -0.1 & 0.1 \\
\hline analysis & -0.2 & 0.1 & -0.1 & -0.1 & -0.2 & -0.3 & -0.4 & -0.3 & -0.3 & -0.3 & -0.4 & -0.3 & -0.4 & -0.4 & -0.4 & -0.4 & -0.4 & -0.3 & $3-0.2$ & -0.2 & -0.3 & 0.1 \\
\hline
\end{tabular}


Referring to Table 9 in which the document context is set to those documents in which pcr occurs, we can see that after 1990, polymerase chain reaction occurs in fewer documents with pcr than would be expected given the feature associations of the two terms. And as we saw in Table 5, Table 9 also clearly shows that the terms real time, and real time pcr gradually increase in co-occurrence with pcr after 2000, indicating the rise of an automated and quantitative technology based on PCR. It can also be seen that the variance among term associations is a lot less in Table 9 (pcr) than in Table 8 (polymerase chain reaction). This is because Table 8 uses the term for the original disruptive technology that was quickly replaced to a large degree, whereas Table 9 uses a term that is still very much in use.

Table 9 Difference of similarities for document associations and feature associations by year to the term pcr.

\begin{tabular}{|c|c|c|c|c|c|c|c|c|c|c|c|c|c|c|c|c|c|c|c|c|c|c|}
\hline \multicolumn{23}{|c|}{ difference of czekanowski coefficients (doc - feature) in context of "pcr" } \\
\hline term & $\begin{array}{l}\infty \\
\infty \\
\stackrel{-}{-1}\end{array}$ & $\begin{array}{l}\text { の } \\
\text { ๙ે }\end{array}$ & ᄋ̆ & ब్ન & ન్ & શે & बু & ஜ & $\begin{array}{l}\text { ڤ్ } \\
\text { م్ }\end{array}$ & बे & 文 & ब & ○ 응 & 공 & 옹 & $\stackrel{m}{\text { ঠ̊ }}$ & ষ্ণ & 옹 & ○̊ & 옹 & $\begin{array}{l}\infty \\
\text { ○ } \\
\text { ○ }\end{array}$ & $\frac{\text { std. }}{\text { dev. }}$ \\
\hline pcr & 0.0 & 1.0 & 1.0 & 0.9 & 0.8 & 0.8 & 0.8 & 0.8 & 0.8 & 0.8 & 0.7 & 0.8 & 0.8 & 0.8 & 0.8 & 0.8 & 0.9 & 0.9 & 0.9 & 0.9 & 0.9 & 0.2 \\
\hline real time & 0.0 & 0.0 & 0.0 & 0.0 & 0.0 & 0.0 & 0.0 & 0.0 & 0.0 & 0.0 & 0.0 & 0.0 & 0.1 & 0.1 & 0.2 & 0.3 & 0.4 & 0.4 & 0.3 & 0.3 & 0.3 & 0.1 \\
\hline polymerase chain reaction pcr & 0.0 & 0.5 & 0.3 & 0.1 & 0.0 & 0.1 & 0.0 & 0.0 & 0.0 & 0.0 & 0.0 & 0.0 & 0.0 & 0.0 & 0.0 & 0.0 & 0.0 & 0.0 & 0.0 & 0.0 & 0.0 & 0.1 \\
\hline time & 0.0 & 0.1 & 0.0 & 0.0 & 0.0 & 0.0 & 0.0 & 0.0 & 0.0 & 0.0 & 0.0 & 0.1 & 0.1 & 0.1 & 0.2 & 0.2 & 0.3 & 0.4 & 0.3 & 0.3 & 0.3 & 0.1 \\
\hline polymerase chain & 0.0 & 0.5 & 0.3 & 0.1 & 0.0 & 0.1 & 0.0 & 0.0 & 0.0 & 0.0 & 0.0 & 0.0 & 0.0 & 0.0 & 0.0 & 0.0 & 0.0 & 0.0 & 0.0 & 0.0 & 0.1 & 0.1 \\
\hline real time pcr & 0.0 & 0.0 & 0.0 & 0.0 & 0.0 & 0.0 & 0.0 & 0.0 & 0.0 & 0.0 & 0.0 & 0.0 & 0.0 & 0.1 & 0.1 & 0.2 & 0.2 & 0.3 & 0.2 & 0.1 & 0.3 & 0.1 \\
\hline rt & 0.0 & 0.0 & 0.2 & 0.0 & 0.0 & 0.0 & 0.2 & 0.2 & 0.3 & 0.2 & 0.2 & 0.3 & 0.2 & 0.2 & 0.3 & 0.2 & 0.3 & 0.2 & 0.1 & 0.3 & 0.1 & 0.1 \\
\hline reaction & 0.0 & 0.5 & 0.3 & 0.2 & 0.1 & 0.2 & 0.1 & 0.1 & 0.1 & 0.1 & 0.1 & 0.1 & 0.1 & 0.0 & 0.1 & 0.0 & 0.0 & 0.1 & 0.1 & 0.1 & 0.2 & 0.1 \\
\hline rt pcr & 0.0 & 0.0 & 0.2 & 0.0 & 0.0 & 0.0 & 0.1 & 0.2 & 0.3 & 0.2 & 0.2 & 0.3 & 0.2 & 0.2 & 0.3 & 0.2 & 0.3 & 0.2 & 0.1 & 0.3 & 0.1 & 0.1 \\
\hline dna & -0.1 & 0.0 & -0.1 & 0.0 & 0.2 & 0.0 & 0.0 & 0.0 & 0.0 & 0.1 & 0.1 & 0.1 & 0.0 & 0.1 & 0.0 & 0.1 & 0.1 & 0.2 & 0.2 & 0.2 & 0.1 & 0.1 \\
\hline polymerase & 0.0 & 0.4 & 0.2 & 0.1 & 0.1 & 0.1 & 0.1 & 0.1 & 0.1 & 0.1 & 0.1 & 0.0 & 0.0 & 0.0 & 0.0 & 0.0 & 0.0 & 0.0 & 0.0 & 0.0 & 0.1 & 0.1 \\
\hline method & 0.0 & 0.1 & 0.0 & 0.1 & 0.3 & 0.1 & 0.1 & 0.1 & 0.2 & 0.2 & 0.1 & 0.2 & 0.1 & 0.1 & 0.1 & 0.2 & 0.2 & 0.3 & 0.2 & 0.2 & 0.3 & 0.1 \\
\hline genes & 0.0 & 0.1 & 0.3 & 0.0 & 0.1 & 0.1 & 0.0 & 0.0 & 0.0 & 0.1 & 0.1 & 0.1 & 0.0 & 0.1 & 0.1 & 0.1 & 0.3 & 0.1 & 0.2 & 0.2 & 0.0 & 0.1 \\
\hline amplification & 0.0 & 0.3 & 0.4 & 0.4 & 0.3 & 0.3 & 0.2 & 0.2 & 0.3 & 0.2 & 0.3 & 0.3 & 0.3 & 0.2 & 0.2 & 0.3 & 0.1 & 0.2 & 0.3 & 0.2 & 0.2 & 0.1 \\
\hline pcr amplification & 0.0 & 0.2 & 0.3 & 0.2 & 0.1 & 0.2 & 0.1 & 0.1 & 0.1 & 0.1 & 0.1 & 0.1 & 0.2 & 0.1 & 0.1 & 0.2 & 0.1 & 0.0 & 0.1 & 0.1 & 0.1 & 0.1 \\
\hline
\end{tabular}

\subsection{Conclusion}

We have shown several methods that support the identification of morphing terminology and terminology transitions over time that aid users in identifying new technologies and their precursors, as well as new applications and combinations of science and technology. We expect that users will be interested in exploring terminology transitions in relation to a focused context, defined through a set of documents, search terms, or computed themes. Temporal analysis of terms' document occurrences, cooccurrences, and associations within the user-defined context will reveal terms that are transitioning into or out of that context. The surprise and emergence algorithms can be applied to term document occurrences and term document co-occurrences to identify terms whose statistically significant changes are temporally aligned, suggesting that one term is replacing or morphing into another term.

The temporal variance of terms' proportionate counts of occurrences, co-occurrences or associations relative to a defined context provides a useful ranking metric to identify those terms that have transitioned the most in that context. The comparison of terms' feature associations and document associations provides a means to evaluate whether terms are being used as expected, or whether they are dropping out of (or into) a given context unexpectedly. This method also enables identification of terms that should appear in documents together based on their feature associations, regardless of whether they do in fact cooccur within documents. 


\subsection{References}

Bookstein A, ST Klein, and T Raita. 1998. "Clumping Properties of Content-Bearing Words.” J. Am. Soc. Inf. Sci. 49(2): 102-114. DOI= http://dx.doi.org/10.1002/(SICI)1097-4571(1998)49:2<102::AIDASI2>3.0.CO;2-2

Engel, DW, PD Whitney, AJ Calapristi, and FJ Brockman. 2009. "Mining for Emerging Technologies within Text Streams and Documents." In Proceedings for the Society of Industrial and Applied Mathematics (SIAM) International Conference on Data Mining (SDM09), Reno, NV, 2009.

Engel, DW, PD Whitney and NO Cramer. 2010. "Events and Trends in Text Stream.” In Text Mining: Application and Theory, eds. M Berry and J Kogan. John Wiley \& Sons, Chichester, United Kingdom.

Rose, SJ, DW Engel, NO Cramer, and WE Cowley. 2010. "Automatic Keyword Extraction from Individual Documents." In Text Mining: Application and Theory, eds. M Berry and J Kogan, John Wiley \& Sons, Chichester, United Kingdom. 



\section{Appendix A}

200 Terms of Interest in BioTechniques dataset, as extracted by RAKE.

\begin{tabular}{|c|c|c|}
\hline dna & cat activity & laser capture microdissection \\
\hline site directed mutagenesis & $\operatorname{sscp}$ & hsv \\
\hline polymerase chain reaction & strand cdna synthesis & reverse transcription rt pcr \\
\hline green fluorescent protein & t7 dna polymerase & cell lines \\
\hline real time pcr & dna methylation & reportergene \\
\hline gfp & automated dna sequencer & sequencing \\
\hline dna sequence & denaturing gradient gel electrophoresis & sequences \\
\hline pcr & methylation status & protein expression \\
\hline single nucleotide polymorphism snp & dna sequence analysis & gel electrophoresis \\
\hline agarose gel electrophoresis & gene expression analysis & sequencing reactions \\
\hline gram negative bacteria & dna yields & real time quantitative $p c r$ \\
\hline taq dna polymerase & molecular weight dna & adherent cells \\
\hline reverse transcription pcr rt pcr & pulsed field gel electrophoresis & purified dna \\
\hline cell growth & quantitative real time pcr & apoptotic cells \\
\hline dna fragments & endothelial cells & differential displaydd \\
\hline genomic dna & reverse transcription $\mathrm{pcr}$ & quantitative pcr \\
\hline cdna library & ribonuclease protection assay & pcr technique \\
\hline automated dna sequencing & quantitative rt pcr & peripheral blood cells \\
\hline differentially expressed genes & virus & phage particles \\
\hline performance liquid chromatography & peptide & extracted dna \\
\hline dna polymerase & recombinant protein & polymerase chain reaction products \\
\hline cells & gene & cloning strategy \\
\hline polymerase chain reaction pcr & enzyme linked immunosorbent assay elisa & positively charged nylon membrane \\
\hline dna sequencing & gel & flag peptide \\
\hline protein & dna sequences & cloning vectors \\
\hline rna degradation & dna polymerases & allele specific primers \\
\hline rt & dna fragment & protein dna interaction \\
\hline paraffin embedded tissues & oligonucleotide probes & fluorescent detection \\
\hline fusion protein & cell & protein kinases \\
\hline green fluorescent protein $\mathrm{gfp}$ & template dna & fluorescent proteins \\
\hline rna & pcramplification & qpcr \\
\hline human genomic dna & dna binding proteins & quantitative reverse transcription $\mathrm{pcr}$ rt pcr \\
\hline double stranded dna & beta gal & fret \\
\hline plasmid dna & chromosomal dna & randomly amplified polymorphic dna rapd \\
\hline dna templates & gene expression data & rapd \\
\hline pcr products & aequorea victoria green fluorescent protein gfp & rapid cycle pcr \\
\hline gene expression & scfv & contaminating genomic dna \\
\hline rt pcr & single base mutations & recombinant antibody fragments \\
\hline protein protein interactions & single stranded conformational polymorphism sscp & recombinant dna technology \\
\hline beta galactosidase beta gal & direct dna sequencing & regulated expression \\
\hline cloned dna & transgene expression & rna binding proteins \\
\hline reverse transcription polymerase chain reaction rt pcr & dna damage & rna preparations \\
\hline denaturing gradient gel electrophoresis dgge & vaccinia virus & dd \\
\hline target protein & vh & silverstaining \\
\hline dna binding & live cell imaging & human dna \\
\hline methylation & allele specific pcr & slab gel electrophoresis \\
\hline microa rray data & digoxigenin labeled probes & sscp analysis \\
\hline gene expression profiling & methylation analysis & hybridoma cell lines \\
\hline enhanced green fluorescent protein egfp & electrophoretic mobility shift assay & study protein protein interactions \\
\hline single stranded dna & cell surface antigens & insect cells \\
\hline single nucleotide polymorphisms snps & double stranded dna fragments & dna binding activity \\
\hline expression & paraffin embedded tissue sections & transposon \\
\hline cell line & pcr amplified dna & tta \\
\hline recombinant virus & multiplexpcr & laser capture microdissection Icm \\
\hline per product & protein dna interactions & cell death \\
\hline system & basal expression & baculovirus expression system \\
\hline phage & agarose gels & mab \\
\hline total rna & probes & markergene \\
\hline target dna & dna probes & matrigel \\
\hline cycle sequencing & dna microarray & detection system \\
\hline assay & mass spectrometry ms & cell monolayers \\
\hline pcr primers & real time reverse transcription $p c r$ rt pcr & double stranded dna sequencing \\
\hline program & single strand conformation polymorphism sscp & enhanced green fluorescent protein \\
\hline expression level & transfected cells & microa rray experiments \\
\hline quality rna & method & filamentous fungi \\
\hline gene expression patterns & dna template & ligation mediated pcr \\
\hline gfp fluorescence & \multicolumn{2}{|c|}{ sodium dodecyl sulfate polyacrylamide gel electrophoresis sds page } \\
\hline
\end{tabular}




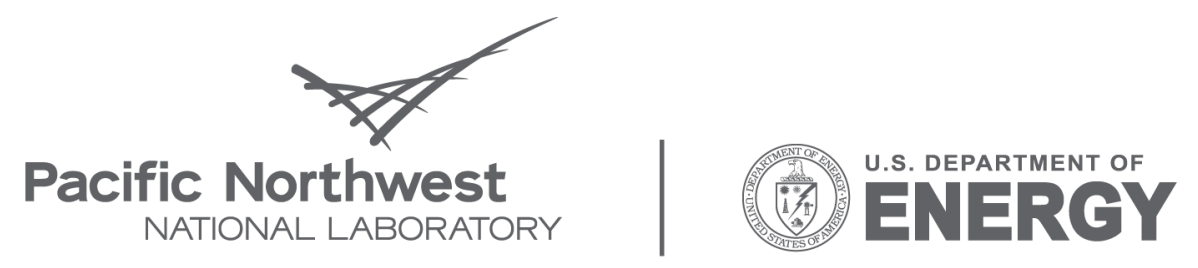

Proudly Operated by Battelle Since 1965

902 Battelle Boulevard

P.O. Box 999

Richland, WA 99352

1-888-375-PNNL (7665)

www.pnl.gov 